\title{
Color Properties and Stabilizing Effect of Metal Ion on Anthocyanin from Buni (Antidesma bunius) Fruit
}

\author{
Swanty Rahmazania Mustika ${ }^{1}$, Abdullah Muzi Marpaung ${ }^{1, *}$ \\ ${ }^{1}$ Food Technology Department, Swiss German University, Tangerang, Indonesia \\ "Corresponding author. Email: bangmuzi@yahoo.com
}

\begin{abstract}
The objectives of this research were to evaluate the possibility of metal complexation in generating blue color, and the stability of the anthocyanin from Buni (Antidesma bunius) fruit extract. Four different metals ions $\left(\mathrm{Ca}^{2+}, \mathrm{Mg}^{3+}, \mathrm{Al}^{3+}\right.$, and $\left.\mathrm{Fe}^{3+}\right)$ have tested at three concentrations level $(0 \mathrm{ml}, 0.01 \mathrm{ml}$, and 0.02 $\mathrm{ml}$ of $0.1 \mathrm{~N}$ solution per $\mathrm{ml}$ extract). The divalent $\mathrm{Ca}^{2+}$ and $\mathrm{Mg}^{2+}$ ions made an impact minimally to the bathochromic and hyperchromic shift at $\mathrm{pH} 3-8$. The trivalent $\mathrm{Fe}^{3+}$ successfully generated a bluer color at all $\mathrm{pH}$, while the $\mathrm{Al}^{3+}$ did not work only at $\mathrm{pH} 3$. Stability test at $\mathrm{pH} 6-8$ showed that the best stability occurred at $\mathrm{pH}$ 6. However, the metal complexation samples performed lower stability than the control samples.
\end{abstract}

Keywords: anthocyanin, bathochromic shift, co-pigmentation, hyperchromic shift, metal ion

\section{INTRODUCTION}

Anthocyanin recognized as one of the most potent natural colorants because of its solubility in water, a wide range of color, relatively low toxicity, and functional benefit [1]. The major constraint of the application of anthocyanin in food products is its low stability, especially at a low acidic and neutral condition [1].

There are several methods to increase the anthocyanin stability, including co-pigmentation, self-association, and metal complexation. Tin $(\mathrm{Sn})$, copper $(\mathrm{Cu})$, iron $(\mathrm{Fe})$, aluminum $(\mathrm{Al})$, magnesium $(\mathrm{Mg})$, and potassium $(\mathrm{K})$ are amongst the most common metal used in the complexation. Only anthocyanins that have more than one free hydroxyl group in the B-ring, such as cyanidin, delphinidin, and petunidin based anthocyanins, are able to form a complex with the metal. The complexation may increase the color intensity (hyperchromic shift) and change the red color into bluer (bathochromic shift) and more stable color [2] as reported to be occurred in delphinidin 3-glucoside [3]

Buni (Antidesma bunius) fruit is a wild plant grown in several mountainous areas in Indonesia such as Java, Bali, and Borneo Island. The fruit reported rich in flavonoids, including anthocyanins [2]. The primary anthocyanins in Buni fruit are cyanidin-O-glucoside and malvidin 3,5diglucoside [2]. In spite of numerous and well-documented studies on the co-pigmentation of anthocyanin, information is lacking on the metal complexation effect of the fruit extract with four different metal ion such as $\mathrm{Ca}^{2+}$, $\mathrm{Mg}^{2+}, \mathrm{Al}^{3+}$, and $\mathrm{Fe}^{3+}$ in the development of blue color.

\section{METHODS}

\section{Materials}

This Buni fruits (Bekasi, West Java, Indonesia) washed, steam-blanched for six minutes, freeze-dried for 72 hours, powdered and sieved through $250 \mu \mathrm{m}$ screen. The powder packed in a tight container and kept in a freezer until used. The chemical used were Folin-Ciocalteu reagent, sodium carbonate, sodium acetate, monobasic potassium phosphate, dibasic potassium phosphate, ferric (III) chloride, aluminum (III) chloride, calcium (II) chloride, magnesium(II) (Merck, Darmstadt, Germany), thanol 96\%, $\mathrm{HCl} 36 \%$, DPPH (2,2-diphenyl-1-picrylhydrazyl) and glacial acetic Acid 99.9\% (Sigma-Aldrich, St. Louis, MO). All chemicals were analytical grade and used without further purification. Buffer solution $\mathrm{pH} 3-6$ was made from sodium acetate and acetic acid. Buffer solution $\mathrm{pH} 7$ - 8 was made from monobasic potassium phosphate and dibasic potassium phosphate.

\section{Extraction}

One gram of buni powder extracted in $40 \mathrm{ml}$ of $0.1 \mathrm{M} \mathrm{HCl}$ with no light and continuous shaking for 30 minutes, followed by centrifugation at $8000 \mathrm{rpm}$ for 4 minutes. The supernatant and liquid separated using Whatman filter paper No 1. 


\section{The Addition of Metal Ion}

The extract diluted with buffer solution $\mathrm{pH} 3-8$ with a dilution factor (DF) of 10 . The $0.1 \mathrm{~N}$ metal ion solution was added to each diluted extract at three levels of ratio: 0 , 0.01 , and $0.02 \mathrm{ml}$ per $\mathrm{ml}$ extract. All samples were equilibrated for around 1 hour at room temperature. The absorption spectra of samples were monitored using a UVVis spectrophotometer (Genesys 10uv Thermo Electron Corporation, USA). A bathochromic shift $\left(\Delta_{\lambda \max }\right)$ was detected as a shift of wavelength expressed in $\mathrm{nm}$ and Hyperchromic effect $(\% \mathrm{~A})$ as an increase in the absorbance value at $\lambda_{\text {vis-max }}$. Hyperchromic effect $(\% \mathrm{~A})$ were calculated with the equation:

$$
\% A=\frac{A-A_{0}}{A_{0}} \times 100 \%
$$

$\mathrm{A}_{0}$ was the absorbance at $\lambda_{\text {vis-max }}$ of sample without metal ions, A was the absorbance at $\lambda_{\text {vis-max }}$ of sample with metal ions, and $\lambda_{\text {vis-max }}$ was the wavelength at visible region that give the highest absorbance.

\section{Color Intensity Analysis}

The color intensity (CI) measured as:

$$
\mathrm{CI}=\left(\mathrm{A}_{\lambda \text { vis-max }}-\mathrm{A}_{700)} \mathrm{X} \mathrm{DF}[4]\right. \text {. }
$$

$\mathrm{A}_{\lambda \text { vis-max }}$ was the absorbance at $\lambda_{\text {vis-max, }} \mathrm{A}_{700}$ was the absorbance at $700 \mathrm{~nm}$, and DF was the dilution factor.

\section{Degradation Kinetics}

Color lost assumed to follow first-order degradation kinetics, and linear regression analysis was used to determine acceptability of the treatments. The k-values and $t(1 / 2)$ values for the first-order reactions were determined using the following equation:

$n \frac{A_{t}}{A_{0}}=-k \times t$.

$t_{1 / 2}=-\ln 0.5 \times k^{-1}$

\section{RESULTS AND DISCUSSION}

The color and visible light absorbance of buni extract at $\mathrm{pH} 3-8$ are depicted in Figure 1. The $\lambda \max$ of the extract at $\mathrm{pH}$ 3-8 was 523, 528, 534, 556, 576, and $591 \mathrm{~nm}$, respectively. The highest intensity of the extract appeared at $\mathrm{pH} 8$, while the lowest intensity occurred at $\mathrm{pH} 5$. Based on the color intensity, the buni extract might be considered

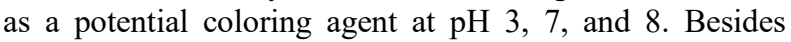
color intensity, the browning index (the ratio between the absorbance at $420 \mathrm{~nm}$ and the absorbance at $\lambda \max$ ) is also important to determine the quality of the extract as a coloring agent [1]. The browning index of the extract at $\mathrm{pH}$ 3,7 , and 8 was $0.34,0.73$, and 0.58 . The low browning index is favorable. Therefore, the highest quality of buni extract as a coloring agent appeared at $\mathrm{pH} 3$.

\section{The Effect of Metal Addition}

Four metal ions - two divalent ions and two trivalent ions were investigated in this study. Visually, $\mathrm{Fe}^{3+}$ was the most affecting ion to the color shift of buni extract at all $\mathrm{pH}$ studied (Figure 2). The spectrophotometric observation showed that the divalent ions $\left(\mathrm{Ca}^{2+}\right.$ and $\left.\mathrm{Mg}^{2+}\right)$ gave no impact or tended to slightly decrease the color of the extract at all $\mathrm{pH}$ studied. Meanwhile, the trivalent ions $\left(\mathrm{Al}^{3+}\right.$ and $\left.\mathrm{Fe}^{3+}\right)$ showed the color shift at all $\mathrm{pH}$ studied, except $\mathrm{Al}^{3+}$ at pH 3.

There are two types of spectroscopic shift: vertical and horizontal shift. The vertical shift is related to the chroma or saturation (intensity). The hyperchromic shift (upward shift) indicate the increase of color intensity, while the hypochromic shift (downward shift) indicate the decrease of color intensity. The horizontal shift is related to the hue. The bathochromic shift (shift to the right or to the longer wavelength) indicates the change of hue to bluer, while the hypsochromic shift (shift to shorter wavelength) indicates the change to redder hue.
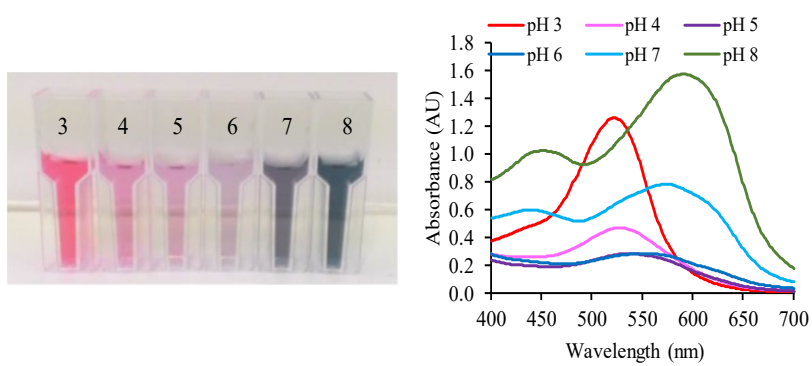

Figure 1. color and light absorbance of buni extract at $\mathrm{pH} 3$ to 8

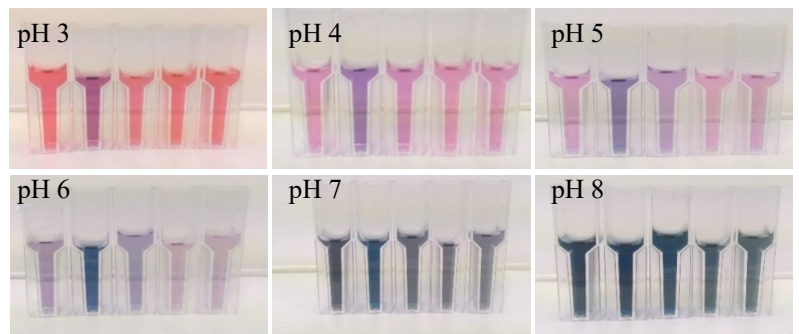

Figure 2. Color changes of anthocyanin at $\mathrm{pH}(3-8)$ after metal complexation with (from left to right): control, $\mathrm{Fe}^{3+}, \mathrm{Al}^{3+}, \mathrm{Mg}^{2+}$, and $\mathrm{Ca}^{2+}$

The higher amount of trivalent ions added gave higher both hyperchromic and bathochromic shift. The range of hyperchromic shift was 1.82 to $330.20 \%$ of the initial intensity. The range of bathochromic shift was 2 to $29 \mathrm{~nm}$. The $\mathrm{Fe}^{3+}$ caused a higher hyperchromic shift than $\mathrm{Al}^{3+}$ in the extract at all $\mathrm{pH}$ studied. 
The highest hyperchromic shift by $\mathrm{Fe}^{3+}$ was in the extract at $\mathrm{pH} 6$ followed by at $\mathrm{pH} 5,4,7$, and 8 . Meanwhile, the order of the hyperchromic shift by $\mathrm{Al}^{3+}$ from the highest to the lowest was at $\mathrm{pH} 6,5,8$, and 3 . It was assumed due to the anthocyanin species at $\mathrm{pH} 6$, which was neutral quinoidal base already converted to the anionic quinoidal base by the presence of metal ion.

Since the neutral quinoidal base has no charged in flavylium ring and less acidic environment at $\mathrm{pH} 6$, so it was easier for metal with positive charge coordinates with anthocyanin and gave an intense blue color.

The greatest bathochromic shift occurred in the extract at $\mathrm{pH}$ 6. The $\mathrm{Fe}^{3+}$ and $\mathrm{Al}^{3+}$ bathochromically shifted the color of 26 and $18 \mathrm{~nm}$, respectively. The shift was likely due to the electron configuration of each metal. $\mathrm{Fe}^{3+}$ ion was thought in a high spin configuration, which having one electron in each of the $\mathrm{d}$ orbitals. Whereas $\mathrm{Al}^{3+}$ only had one electron in the $\mathrm{P}$ orbitals. For divalent metal ions were greater that divalent, it was suggested due to the ion-dipole interaction, which $\mathrm{Mg}^{2+}$ and $\mathrm{Ca}$ had lower positive charged, causing a minimum shift of bathochromic [5].

\section{The Stability Test}

The color stability of anthocyanin complexed by $0.2 \mathrm{ml} 0.1$ $\mathrm{N} \mathrm{FeCl}_{3} / \mathrm{ml}$ extract $\left(\mathrm{ACN}-\mathrm{Fe}^{3+}\right.$ ) was observed at $\mathrm{pH} 6$ to 8 both at room and refrigerator temperature. In accordance with the previous research that the color stability of anthocyanin decrease as the $\mathrm{pH}$ increase [6], the color of buni extract at $\mathrm{pH} 6$ was much more stable than at $\mathrm{pH} 7$ and 8 (Table 1). The $\mathrm{t}_{1 / 2}$ of the extract at $\mathrm{pH} 7$ and 8 were shorter than two days. Meanwhile, the color stability of buni extract at $\mathrm{pH} 6$ was 8.48 to 27.18 days.

As seen in Table 1, the anthocyanin complexation with iron was proven to improve the color stability. The same effect of metal complexation was also reported to be occurred in different berry products [6]. In contrast, the addition of $\mathrm{Fe}^{3+}$ tended to decrease the color stability of buni extract at $\mathrm{pH}$ 6 .

Figure 1 depicted that buni extract demonstrated the lowest intensity at $\mathrm{pH} 5$ and 6 . The pale color indicated that the predominant species of anthocyanin at respective $\mathrm{pH}$, while the remaining red color might contributed by the polymeric anthocyanin that relatively stable. Therefore, the color stability of the extract was relatively high.

The hydration of red flavylium cation to colorless hemiketal is a reversible reaction. The addition of $\mathrm{Fe}^{3+}$ converted the simple anthocyanin to an anthocyanin-iron complex and reverse the hemiketal to flavylium cation. The flavylium cation deprotonated to quinoidal base to form the blue color. However, the low stability indicated that the complex was relatively weak and tended to destruct during storage. Further research is needed (i) to reveal the mechanism of the complexation, (ii) to understand how the complex destructed, and (iii) to improve the complex stability.

\section{CONCLUSION}

As a summary, the finding from present study provides detailed color properties information including the hyperchromic shift and bathochromic effect of the copigmentation between anthocyanin and metal ions were obtained. The specific metal ion were found to impact the properties of the observed colors of anthocyanin. Divalent $\mathrm{Mg}^{2+}$ and $\mathrm{Ca}^{2+}$ were impact minimally, inducing very small or did not impact to bathochromic shift and hyperchromic effect. The trivalent metal $\mathrm{Fe}^{3+}$ and $\mathrm{Al}^{3+}$ induced significantly change on the color spectral characteristic of anthocyanin.

Stability studies showed that iron complexation increased the stability of buni extract at $\mathrm{pH} 7$ and 8, but tended to decrease the stability at $\mathrm{pH} 6$.

\section{REFERENCES}

[1] A. M. Marpaung, N. Andarwulan, P. Hariyadi and D. N. Faridah, "Study on Spectral Characteristics of Selected Unacylated, Monoacylated and Polyacylated Anthocyanin Source Plant Extract at Various pH," in 15th ASEAN Conference on Food Science and Technology, Ho Chi Minh City, 2017.

[2] S. Jorjong, L. Butkhup and S. Samappito, "Phytochemicals and antioxidant capacities of MaoLuang (Antidesma bunius L.) cultivars from Northeastern Thailand," Food Chemistry, vol. 181, p. 248-255, 2015.

[3] A. M. Marpaung, I. Zhang and H. Sutanto, "Colour Behaviour and Stability of Anthocyanin in the Blue Flower of Stachytarpheta jamaicensis and Hydrangea macrophylla," IOP Conference Series: Materials Science and Engineering, vol. 532, pp. 1-7, 2019.

[4] A. M. Marpaung, N. Andarwulan, P. Hariyadi and D. N. Faridah, "The colour degradation of anthocyaninrich extract from butterfly pea (Clitoria ternatea L.) petal in various solvents at $\mathrm{pH} 7$," Natural Product Research, vol. 31, no. 6, pp. 2273-2280, 2017.

[5] G. T. Sigurdson, R. J. Robbins, T. M. Collins and M. M. Giusti, "Evaluating the role of metal ions in the bathochromic and hyperchromic responses of cyanidin derivatives in acidic and alkaline $\mathrm{pH}, "$ Food Chemistry, vol. 208, pp. 26-34, 2016.

[6] R. N. Cavalcanti, T. Diego and A. A. M. Maria, " Non-thermal stabilization mechanisms of anthocyanins in model and food systems - An overview," Food Research Int, vol. 44, pp. 499-509, 2111 . 